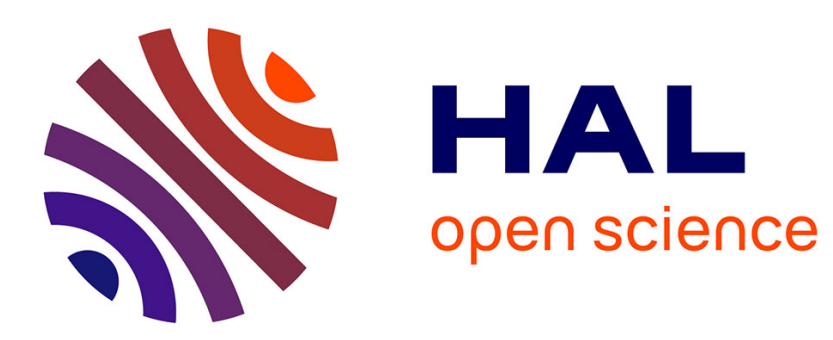

\title{
Comparative chemistry of 18-electron Mo(II) and 17-electron Mo(III) compounds containing only carbon-based ligands
}

Rinaldo Poli, Li-Sheng Wang

\section{- To cite this version:}

Rinaldo Poli, Li-Sheng Wang. Comparative chemistry of 18-electron Mo(II) and 17-electron Mo(III) compounds containing only carbon-based ligands. Coordination Chemistry Reviews, 1998, 178-180, pp.169-189. 10.1016/S0010-8545(98)80121-5 . hal-03310659

\section{HAL Id: hal-03310659 \\ https://hal.science/hal-03310659}

Submitted on 6 Oct 2021

HAL is a multi-disciplinary open access archive for the deposit and dissemination of scientific research documents, whether they are published or not. The documents may come from teaching and research institutions in France or abroad, or from public or private research centers.
L'archive ouverte pluridisciplinaire $\mathbf{H A L}$, est destinée au dépôt et à la diffusion de documents scientifiques de niveau recherche, publiés ou non, émanant des établissements d'enseignement et de recherche français ou étrangers, des laboratoires publics ou privés. 


\title{
Comparative chemistry of 18 -electron Mo(II) and 17-electron Mo(III) compounds containing only carbon-based ligands
}

\author{
Rinaldo Poli ${ }^{\mathrm{a}, *}$, Li-Sheng Wang ${ }^{\mathrm{b}, 1}$ \\ a Laboratoire de Synthèse et d'Electrosynthèse Organometalliques, \\ Faculté des Sciences "Gabriel", Université de Bourgogne, 6 Boulevard Gabriel, \\ 21100 Dijon, France \\ ${ }^{\mathrm{b}}$ Department of Chemistry and Biochemistry, University of Maryland, College Park, \\ MD 20742, USA
}

Received 27 October 1997; received in revised form 3 April 1998; accepted 16 April 1998

\section{Contents}

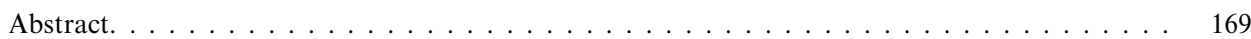

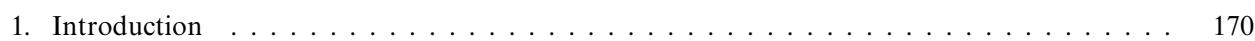

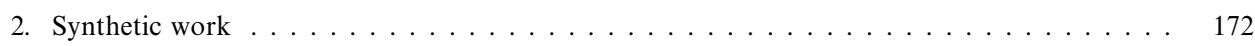

3. Insertion of the diene into the Mo-allyl bond vs. diene substitution . . . . . . . . . . . 176

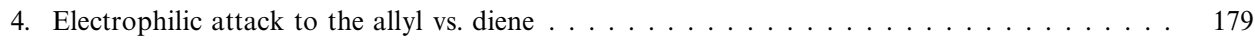

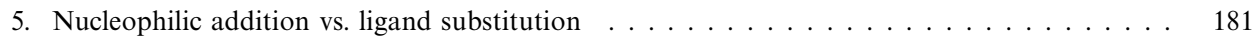

6. Allyl-allyl coupling . . . . . . . . . . . . . . . . . . . . . . . . . . . 185

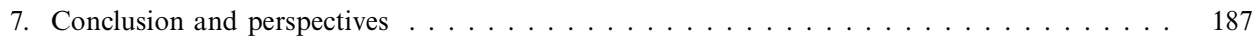

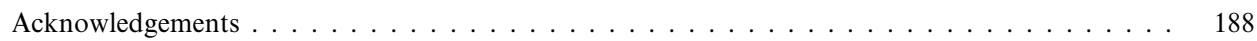

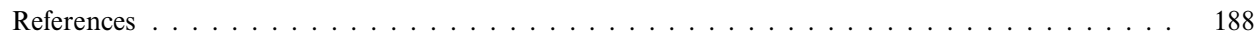

\begin{abstract}
The chemical reactivity of various kinetically stable isomers of compound $\mathrm{CpMo}\left(\eta^{3}-\mathrm{C}_{3} \mathrm{H}_{5}\right)\left(\eta^{4}-\mathrm{C}_{4} \mathrm{H}_{6}\right), \mathbf{1}$, and its oxidation product [1] $]^{+}$, as well as the bis-allyl Mo(III) complex $\mathrm{CpMo}\left(\eta^{3}-\mathrm{C}_{3} \mathrm{H}_{5}\right)_{2}, \mathbf{2}$, and the bis-diene $\mathrm{Mo}(\mathrm{II})$ complex $\left[\mathrm{CpMo}\left(\eta^{4}-\mathrm{C}_{4} \mathrm{H}_{6}\right)_{2}\right]^{+}, \mathbf{3}$, is reviewed. The inertness toward isomerization processes of the allyl and butadiene ligands in the Mo(II) complexes has allowed a study of the relative reactivity toward both electrophilic and nucleophilic addition processes as a function of coordination mode. The dependence of various reaction pathways on the metal oxidation state has also been investigated. Of particular interest is the discovery that the electronically unsaturated intermediate of the butadiene isomerization process is more easily accessible for Mo(III) than for Mo(II). This finding
\end{abstract}

\footnotetext{
* Corresponding author. Fax: +3303803960 98; e-mail: rinaldo.poli@u-bourgogne.fr ${ }^{1}$ Present address: Laboratory for Molecular Structure and Bonding, Department of Chemistry, Texas A\&M University, College Station, TX 77843, USA.
} 
might have relevance for the development of paramagnetic molecules with catalytic activity.

Keywords: Allyl ligands; Butadiene dimerization; Butadiene polymerization; Molybdenum; Paramagnetic organometallics; Reactivity of coordinated ligands

\section{Introduction}

The understanding of the molecular and electronic structure of coordination compounds is a necessary gateway for the rationalization of their reactivity. Certain reactions such as nucleophilic additions are orbitally controlled, others such as protonation are charge controlled. In both cases, knowledge of a particular feature of the electronic structure (atomic orbital participation in the LUMO, charge distribution) can help rationalize the site of attack. In many catalytic cycles, the catalytic action is initiated by a ligand dissociation, which is facilitated by steric crowding or by the electronic stabilization of the unsaturated intermediate. It is important, therefore, to appreciate what factors influence the relative energy of an unsaturated intermediate. More important still would be a knowledge of the structure and relative energy of transition states.

For some time, we have considered the idea that unsaturated intermediates could be stabilized by the adoption of a higher spin state relative to the more saturated starting complex and that, consequently, a change of spin state along an organometallic reaction pathway could be held responsible in some cases for a faster than expected rate [cf. Fig. 1 ( $a$ and b)]. This idea comes from the observation that many stable unsaturated complexes are often found to possess unpaired electrons [1]. Unsaturated reaction intermediates (for instance, a 16-electron complex generated

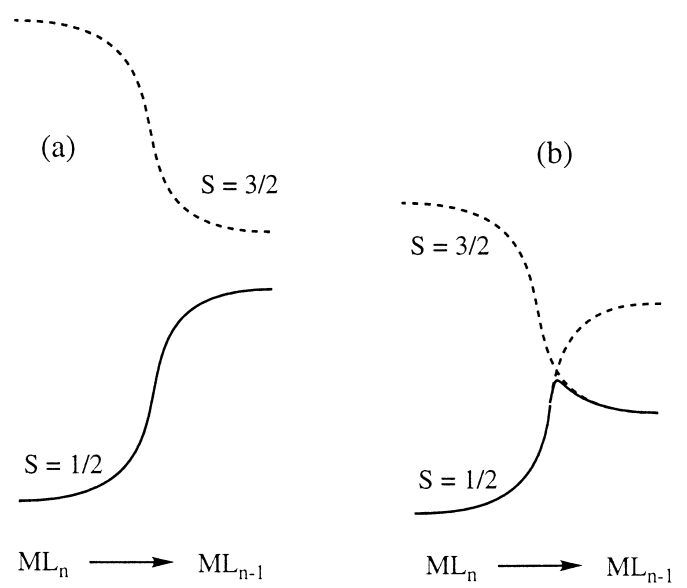

Fig. 1. Qualitative reaction coordinate for a ligand dissociation process from a 17-electron spin doublet complex to afford a 15-electron product that is more stable in either (a) the spin doublet state, or (b) the spin quartet state. 
by ligand dissociation from a saturated complex) are known to be stabilized by weak interactions with donor solvents, or by intra- or intermolecular agostic interactions, or by participation of ligand lone pairs in $\pi$ interactions with the vacant metal orbital. The accelerating effect of each of these stabilizing factors is well appreciated and treated in all current textbooks of inorganic reaction mechanisms. The idea that a dissociative process may be accelerated by a spin state change, however, has not been widely appreciated. This may sound counterintuitive because a spin state change is commonly associated with the idea of "forbiddenness", especially for reaction of organic compounds. On the other hand, this forbiddenness is largely removed by the mixing of spin and orbital angular momenta, which is particularly effective for the heavier elements, leading to rapid intersystem crossing. The relatively old proposals that the strength of the metal- $\mathrm{CO}$ bond in $\mathrm{Cp}_{2} \mathrm{VI}(\mathrm{CO})$ and $\mathrm{Cp}_{2} \mathrm{Cr}(\mathrm{CO})$ is associated with the adoption of a spin triplet state by the resulting $\mathrm{Cp}_{2} \mathrm{VI}$ and $\mathrm{Cp}_{2} \mathrm{Cr}$ products $[2,3]$ has not found a wide generalization to reaction kinetics and mechanisms.

The development of our thinking in this area is detailed in another recent account [4]. In brief, the results of our experimental as well as computational studies allow the conclusions that open-shell, higher spin complexes enjoy a greater relative stabilization for a lighter metal [for instance, Cr(III) relative to Mo(III)], or when the metal has a higher oxidation state [e.g. Mo(IV) relative to Mo(II)], or with a more electronegative ligand environment [e.g. $\mathrm{CpMoCl}\left(\mathrm{PMe}_{3}\right)_{2}$ relative to $\left.\mathrm{CpMoH}\left(\mathrm{PMe}_{3}\right)_{2}\right]$. Many of our recent studies have involved complexes that contain a mixture of carbon-based ligands (mostly cyclopentadienyl, $\mathrm{Cp}$, or the pentamethyl derivative, $\mathrm{Cp}^{*}$ ) and ligands based on other main group elements as donor atoms (halides, phosphines, ethers, etc.). While the first ones normally stabilize low-valent, diamagnetic systems with an 18-electron configuration, the latter are more typical of Werner-type systems, for which the 18-electron rule plays a less important role and a variability of oxidation states and spin states is more frequently observed. It is therefore logical to expect a hybrid behavior of these systems with respect to the two more classical areas of coordination chemistry [1].

In the present review, we have chosen not to duplicate the analysis of our recent work in intermediate oxidation state organometallics with open-shell configurations, which is available in previous reviews $[1,4]$. Rather, we shall briefly discuss a recent evolution of our interest in this area, which concerns complexes containing only carbon-based ligands. As such, the present review will be rather limited in scope. The question that we asked ourselves at the outset is whether open-shell reaction intermediates (either unobservable, observable, or even isolable) in the more traditional organometallic chemistry area could also enjoy an energetic stabilization related to a spin state change, as they do when they also contain halides and phosphine ligands. A well-known, albeit rare example of spin triplet 16-electron low-valent system is $\mathrm{Fe}(\mathrm{CO})_{4}$ [5]. Our studies have been centered on half-sandwich systems of Mo(II) and Mo(III).

We have sought a simple system where the oxidation state can be changed reversibly between Mo(II) and Mo(III) and where the same elementary steps of ligand transformations could occur in either oxidation state. The model chosen is a 
(previously unknown) half-sandwich system containing both an allyl ligand and a butadiene ligand, [CpMo $\left.\left(\eta^{3}-\mathrm{C}_{3} \mathrm{H}_{5}\right)\left(\eta^{4}-\mathrm{C}_{4} \mathrm{H}_{6}\right)\right]^{n+}$, for either $\operatorname{Mo}(\mathrm{II})(n=0 ; \mathbf{1})$ or $\operatorname{Mo}($ III $)\left(n=1 ;[1]^{+}\right)$. The investigations of these compounds, as well as the previously reported [6] bis-allyl system $\mathrm{CpMo}\left(\eta^{3}-\mathrm{C}_{3} \mathrm{H}_{5}\right)_{2}, 2$, and a novel bis-diene Mo(II) complex, [CpMo $\left.\left(\eta^{4}-\mathrm{C}_{4} \mathrm{H}_{6}\right)_{2}\right]^{+}, \mathbf{3}$, have also provided previously unavailable information on the reactivity of the coordinated diene and allyl ligands as a function of coordination mode. These findings will also be presented in this review.

\section{Synthetic work}

The neutral target system 1 can be considered as a member of the large class of "four-legged piano stool" complexes of Mo(II), in that the four-electron allyl ligand can be seen as occupying two coordination sites in this structure. Such a simple system, somewhat surprisingly, had not been previously reported. We considered that the one-electron oxidation to $[\mathbf{1}]^{+}$could be accessible and that the oxidation product could be a stable system. This is because 17-electron four-legged piano stool complexes of Mo(III) now constitute a relatively large class of derivatives [7], and because the compatibility of both allyl and butadiene ligands with this structural type and oxidation state has been demonstrated for compounds $\mathrm{CpMo}\left(\eta^{3}-\mathrm{C}_{3} \mathrm{H}_{5}\right)_{2}$ and $\mathrm{CpMoCl}_{2}\left(\eta^{4}-\mathrm{C}_{4} \mathrm{H}_{6}\right)[6,8]$.

The correctness of all the above assumptions has subsequently been verified. The synthetic work is summarized in Scheme 1 [9]. The $\mathrm{CpMoCl}_{2}$ starting material is prepared in two high-yield steps from commercially available $\left[\mathrm{CpMo}(\mathrm{CO})_{3}\right]_{2}[10,11]$. The addition of butadiene to $\mathrm{CpMoCl}_{2}$ provides a new, simple synthesis of complex $\mathrm{CpMoCl}_{2}\left(\eta^{4}-\mathrm{C}_{4} \mathrm{H}_{6}\right)$, which was previously available only via a disproportionation process from $\mathrm{CpMoCl}\left(\mathrm{F}_{3} \mathrm{CC} \equiv \mathrm{CCF}_{3}\right)_{2}$ and butadiene [8]. The interaction of this compound with allylmagnesium bromide involves reduction and allyl/chloride metathesis. The intermediate product of reduction has been isolated by carrying out the reaction with one equivalent of the Grignard reagent. Complex $[\mathbf{1}]^{+}$, obtained by ferrocenium oxidation of $\mathbf{1}$, is a rare example of a Mo(III) complex where the metal is bonded only to carbon atoms. Since the reported synthesis of compound $\mathrm{CpMo}\left(\eta^{3}-\mathrm{C}_{3} \mathrm{H}_{5}\right)_{2}, 2$, is multistep and the final yield is not reported [6], we have developed a shorter preparation procedure, in two steps from $\left[\mathrm{CpMo}(\mathrm{CO})_{3}\right]_{2}$, see Scheme 1.

Somewhat surprisingly, but rather fortunately in view of the subsequent development of the chemical investigations, compound 1 exists in three different forms that can be independently isolated in an isomerically pure form and that do not readily interconvert (see Scheme 2). In addition, the product of oxidation is observed in four different isomeric forms, although the isomerization rates are faster in this oxidation state and allow the isolation of only the thermodynamically more stable isomer $[\mathbf{1 b}]^{+}$. The various isomers differ in the stereochemistry of the coordinated allyl and diene ligands. The allyl ligand adopts either a prone, or exo (for a and d) or a supine, or endo (for $\mathbf{b}$ and $\mathbf{c}$ ) geometry, whereas the butadiene ligand adopts either an s-cis supine (for $\mathbf{a}$ and $\mathbf{b}$ ) or an s-trans (for $\mathbf{c}$ and $\mathbf{d}$ ) geometry. An $s$-cis 
$\left[\mathrm{CpMo}(\mathrm{CO})_{3}\right]_{2}$
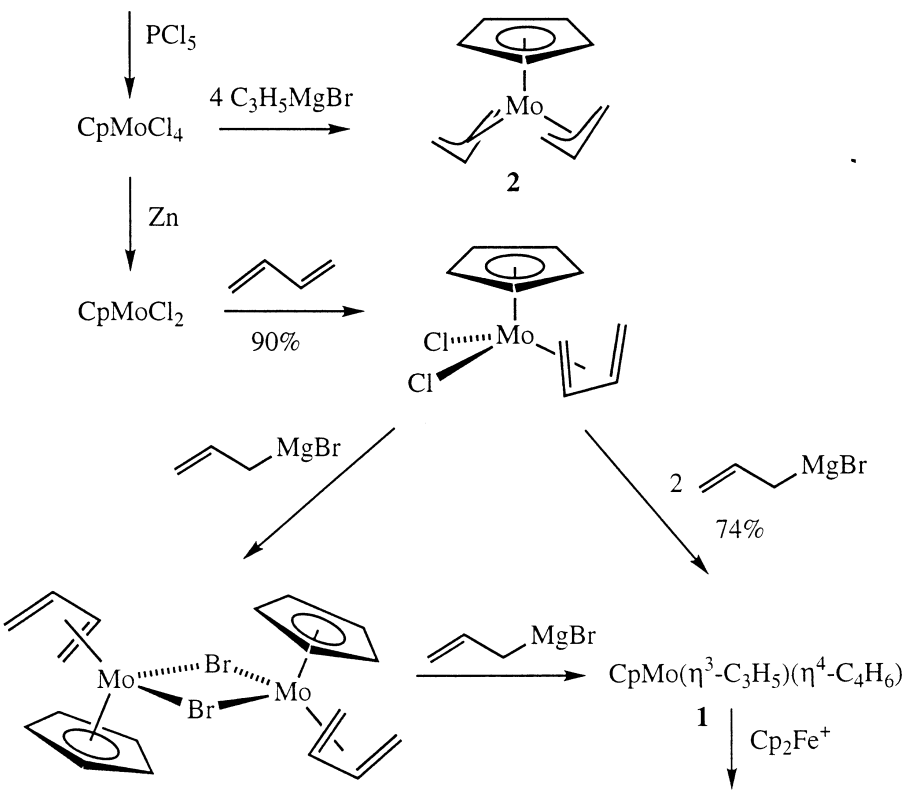

$\left[\mathrm{CpMo}\left(\eta^{3}-\mathrm{C}_{3} \mathrm{H}_{5}\right)\left(\eta^{4}-\mathrm{C}_{4} \mathrm{H}_{6}\right)\right]^{+}$

$[1]^{+}$

Scheme 1.

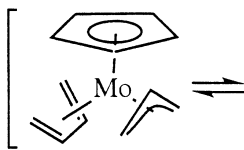

1a

$[\mathbf{1 a}]^{+}$

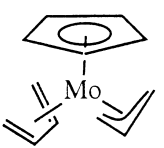

$1 \mathrm{~b}$

$[1 \mathrm{~b}]^{+}$

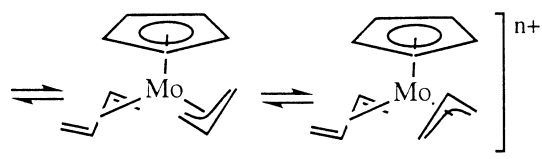

$1 \mathrm{c}$

$[1 \mathrm{c}]^{+}$

$[\mathbf{1 d}]^{+} \quad(\mathrm{n}=1)$

Scheme 2.

prone butadiene ligand has not been observed for this system. All neutral isomers have been characterized by NMR, in addition to single crystal X-ray crystallography for 1a and 1c [see Fig. 2(a and b)], whereas all cationic isomers have been identified by EPR, in addition to an X-ray structure for [1 b] ${ }^{+}$[see Fig. 2(c)].

Isomer 1a is crystallized selectively from the 98:2 equilibrium mixture of $1 \mathbf{a}$ and 1b which is obtained from the synthesis in Scheme 1. Isomer $\mathbf{1 b}$ is obtained selectively by cobaltocene reduction of $[\mathbf{1 b}]^{+}$, while isomer $\mathbf{1 c}$ is generated in equilibrium with 1a and 1b either thermally or photochemically. Pure 1c is then obtained by chromatographic separation on silica, a process which exploits the different reactivity of the three isomers toward sources of acidic protons (vide infra) such as the silanol groups 
(a)

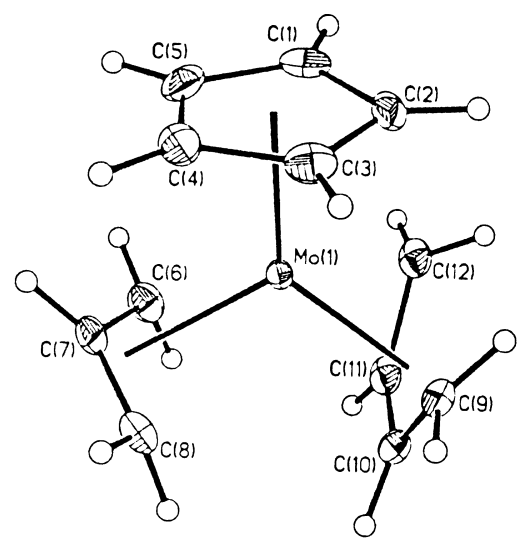

(b)

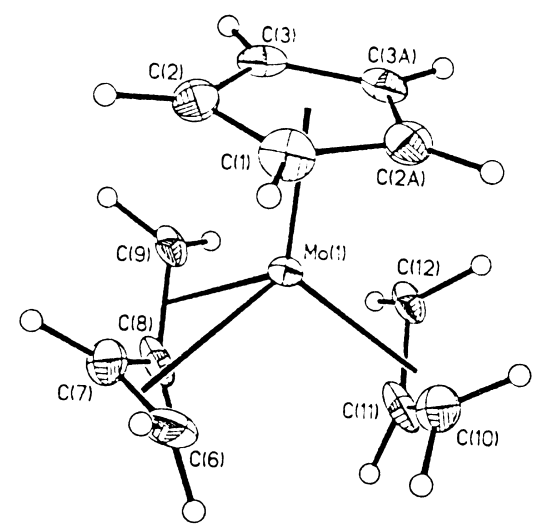

(c)

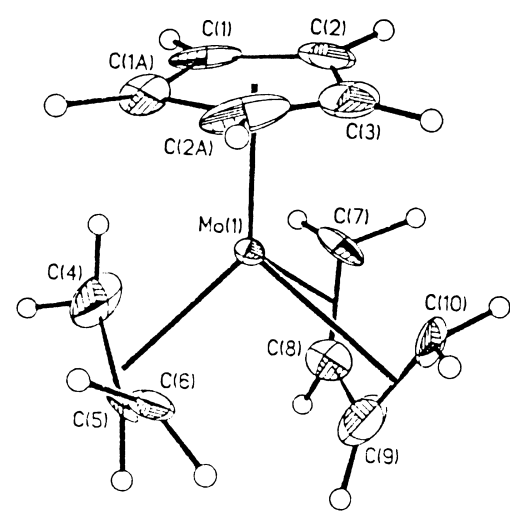

Fig. 2. X-ray structure of: (a) complex 1a; (b) complex 1c; (c) complex [1b $]^{+}$. Copyright 1997 American Chemical Society. 
on the silica surface. Chemical or electrochemical oxidation of the three isomers of $\mathbf{1}$ affords the corresponding cations, the oxidation of $\mathbf{1 c}$ generating both $[\mathbf{1 c}]^{+}$and $[\mathbf{1 d}]^{+}$in rapid equilibrium. All oxidized complexes, however, can only be observed by EPR spectroscopy upon generation at low temperature. Under ambient temperature condition, they all isomerize irreversibly to the most stable isomer $[\mathbf{1 b}]^{+}$. The combination of kinetic, equilibrium, and electrochemical studies have allowed us to fully define the energetics of the systems and the activation barriers to the isomerization processes as shown in Scheme 3 [9].

Several conclusions may be drawn from these studies. The first one is that the coordination mode of the allyl and diene ligands influences the metal electron density (as gauged by the oxidation potential) in an important way. The Mulliken charges calculated for the metal in the different isomers of 1 by DFT methods are in agreement with the experimental results. The suitability of the DFT method for this system is shown by the excellent match $(\leqslant 2 \mathrm{kcal} / \mathrm{mol})$ between experimental and calculated relative energies between isomers, both in the Mo(II) and the Mo(III) manifolds. The calculations show, in particular, that the diene is both a better $\sigma$ donor and a better $\pi$ acceptor when coordinated in the s-cis mode, whereas the metal-allyl bond is more ionic for the prone coordination mode. The latter feature also rationalizes observed differences for rates of proton attack to the allyl position in the different isomers (vide infra).

The most interesting conclusion of this study, however, concerns the different rates of isomerizations in the different oxidation states, always faster (lower barriers, see Scheme 3) for Mo(III) than for Mo(II). While the isomerization of the allyl ligand can be envisaged to occur either via an $\eta^{3} / \eta^{1} / \eta^{3}$ rearrangement (with Mo-C

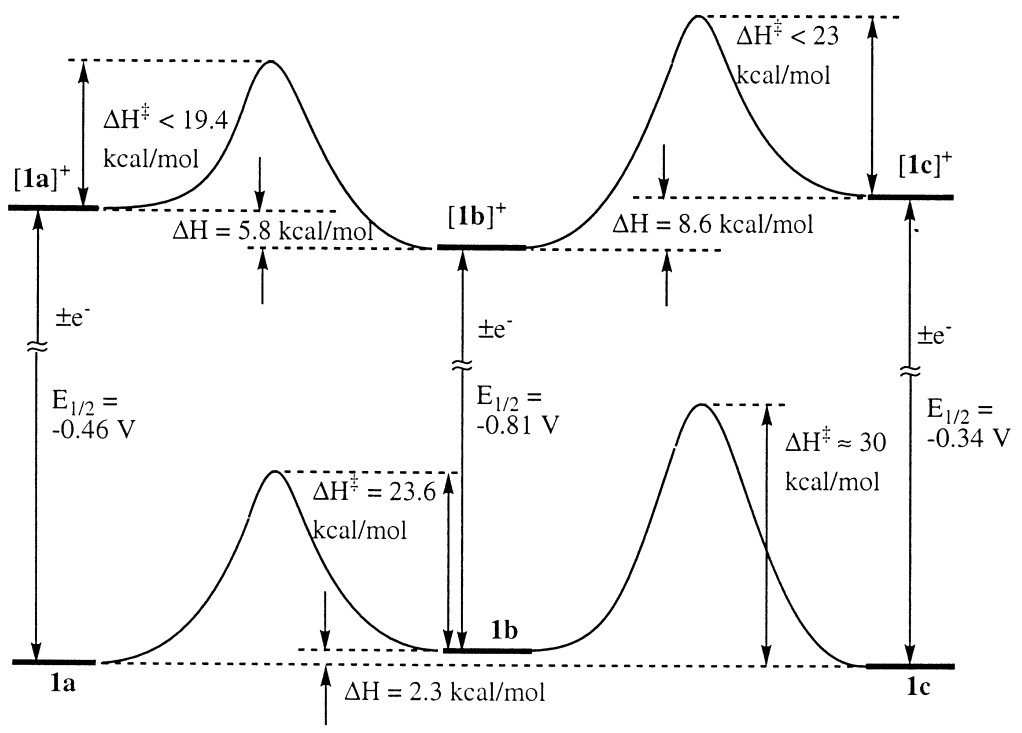

Scheme 3. 
bond breaking and reduction of the number of valence electrons) or via rotation around the Mo-allyl bond (without bond breaking), the isomerization of the diene ligand must necessarily involve $\mathrm{Mo}-\mathrm{C}$ bond breaking and formation of a coordinatively unsaturated $\left[\mathrm{CpMo}\left(\eta^{3}-\mathrm{C}_{3} \mathrm{H}_{5}\right)\left(\eta^{2}-\mathrm{CH}_{2}=\mathrm{CH}-\mathrm{CHCH}_{2}\right)\right]^{n+}$ intermediate (I), which has 16 valence electrons for $n=0$ or 15 valence electrons for $n=1$. Until recently, it was implicitly assumed that a greater departure from the saturated 18-electron configuration would necessarily correspond to less thermodynamic stability (higher energy) [12]. According to this idea, there should be a greater barrier against the dissociation of a ligand from a 17-electron complex relative to an analogous 18-electron complex. The example at hand here, however, clearly shows the opposite trend. Thus, the 15-electron Mo(III) intermediate is more easily accessible from the 17-electron precursor than the 16-electron Mo(II) intermediate from the 18-electron precursor.

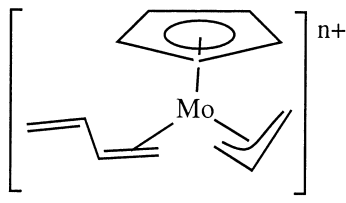

I

What makes the Mo-ene bond weaker for the electronically more deficient system? We can think of more than one possible answer to this question. One could simply assume that, on going from Mo(II) to Mo(III), the expected strengthening of the $\sigma$ bonding component is paralleled by an even more important weakening of the $\pi$ back-bonding component. After all, alkene complexes are rare for metals in high oxidation states. Another (or additional) factor is the possible energetic stabilization of the 15-electron configuration for Mo(III) by the adoption of a spin quartet ground state. These electronic structure and bonding questions are currently being looked at from the theoretical standpoint.

\section{Insertion of the diene into the Mo-allyl bond vs. diene substitution}

Processes of diene polymerization are believed to occur via allyl-diene intermediates and the generally accepted chain growth mechanism involves an insertion of a coordinated diene ligand into a metal-allyl bond. It was therefore of interest to examine the aptitude of both the Mo(II) and Mo(III) complexes to accomplish this insertion step and to possibly function as catalysts for butadiene polymerization. The proposed diene isomerization intermediate $(\mathbf{I})$ is electronically identical to the product of insertion of the diene ligand into the Mo-allyl bond (II), i.e. the proposed intermediate of the butadiene polymerization process. Thus, if the same energetic factors that are giving a greater relative stability to $\mathbf{I}$ for $n=1$ also regulate the relative stability of II, a greater insertion aptitude and perhaps a greater 
catalytic activity for the polymerization of butadiene could be expected for $[\mathbf{1}]^{+}$ relative to $\mathbf{1}$.

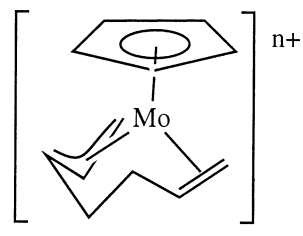

II

Compounds $\mathbf{1}$ and $[\mathbf{1}]^{+}$indeed show catalytic activity for the transformation of dienes. In order to compare the relative activity of neutral and cationic complexes, the sparingly soluble $\mathrm{PF}_{6}^{-}$salt of $[1]^{+}$which is obtained by oxidation of 1 with ferrocenium hexafluorophosphate was metathesized to afford a more soluble $\left[\mathrm{B}\left(\mathrm{C}_{6} \mathrm{H}_{3}\left(\mathrm{CF}_{3}\right)_{2}-3,5\right)_{4}\right]^{-}$salt. There are, however, several problems for both systems: (i) very low activities - only a few turnovers per day are observed under forcing conditions $\left(100{ }^{\circ} \mathrm{C}\right.$ in toluene) for both the neutral and the cationic catalyst; (ii) thermal stability under the conditions that produce the desired catalytic effect (vide infra); (iii) lack of stereoselectivity, leading to mixtures of products. According to ${ }^{1} \mathrm{H}$ and ${ }^{13} \mathrm{C}$ NMR spectroscopy, a ca. 1:1 ratio of polymers (1,4-cis and 1,4-trans) and dimers (4-vinylcyclohexene and 1,5-cyclooctadiene) is obtained, see Scheme 4.

Spectroscopic monitorings of the catalytic processes with $\mathbf{1}$ and $[\mathbf{1}]^{+}$revealed, in the first case, the slow decrease of the concentration of $\mathbf{1}$ in favor of EPR active species, and in the second case, the slow decrease of the concentration of $[\mathbf{1}]^{+}$in favor of diamagnetic species. The catalyst decomposition yields in both cases complex mixtures of products. It is impossible, therefore, to unambiguously establish a relative catalytic activity of $\mathbf{1}$ and $[\mathbf{1}]^{+}$with respect to butadiene polymerization and/or dimerization.

We then asked ourselves whether ligands other than butadiene may induce a cleaner insertion process by irreversibly trapping the intermediate resulting from the insertion step, thus allowing a direct comparison between the reactivities of Mo(II) and Mo(III) complexes. A possible alternative outcome, of course, would be the substitution of the diene ligand via an intermediate such as I. For compound 1, both the diene isomerization process (via intermediate I) and the diene polymerization catalysis require harsh conditions. Therefore, we suspected that a reaction with

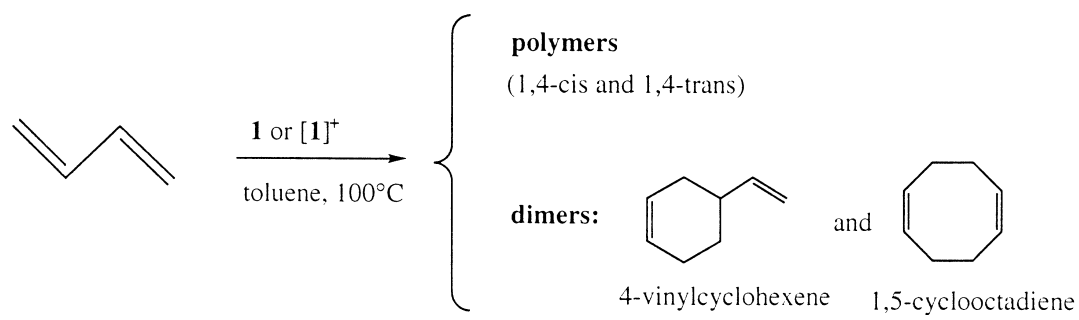

Scheme 4. 
other neutral ligands would also be a difficult process. Indeed, no reaction between 1 and either $\mathrm{MeCN}, \mathrm{CO}, \mathrm{PMe}_{3}$, or $\mathrm{Bu}^{\mathrm{t}} \mathrm{NC}$ occurs at room temperature. However, heating 1 in neat $\mathrm{Bu}^{\mathrm{t}} \mathrm{NC}$ to $100{ }^{\circ} \mathrm{C}$ resulted in the formation of the insertion product $\mathbf{4}$, in addition to lesser amounts of the diene substitution product $\mathbf{5}$. The coordination geometry of the insertion product is as shown in Scheme 5, as shown by detailed NMR studies. Given that the three isomers of $\mathbf{1}$ are free to interconvert under these conditions, we cannot establish which isomer has the greatest insertion reactivity.

The addition of $\mathrm{MeCN}, \mathrm{CO}$, or $\mathrm{PMe}_{3}$ to $[\mathbf{1 c}]^{+}$at room temperature leads to no reaction. Compound $\mathrm{CNBu}^{\mathrm{t}}$, on the other hand, reacts smoothly at room temperature but does not give rise to insertion. Curiously, neither does this interaction lead to substitution of the diene ligand, in spite of the demonstrated (Scheme 3) higher lability of the diene ligand in the Mo(III) system. Rather, elimination of an allyl radical occurs, with formation of the diene-isonitrile complex 6 , see Scheme 6 . Therefore, the reactivity of $[\mathbf{1 c}]^{+}$does not parallel that of the neutral precursor $\mathbf{1}$. Of course, Scheme 3 also indicates the greater lability of the allyl function in the Mo(III) product. Therefore, an initial rearrangement of the allyl ligand from $\eta^{3}$ to $\eta^{1}$ could be followed by a thermodynamically controlled reduction involving allyl radical loss, which appears to be a general reactivity pattern for allyl derivatives of Mo(III). We have found, in fact, that the same process occurs upon adding

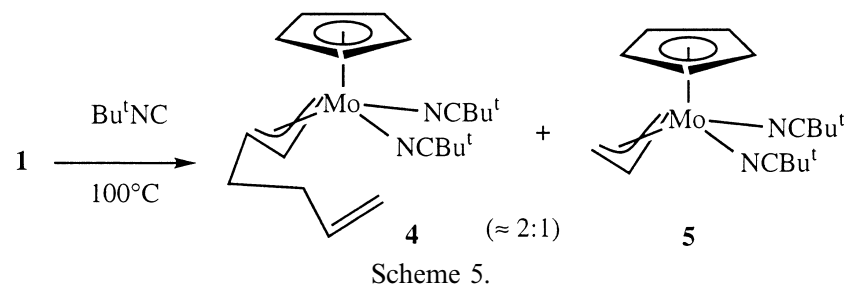

Scheme 5 .

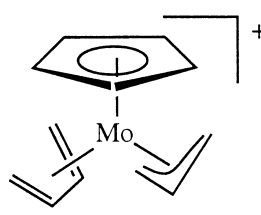

$[1 \mathrm{~b}]^{+}$

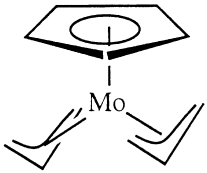

2

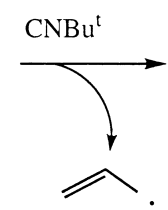

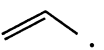

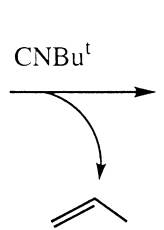

Scheme 6 .
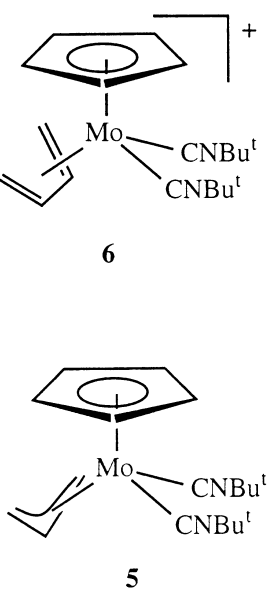
$\mathrm{CNBu}^{\mathrm{t}}$ to compound $\mathbf{2}$ to provide another method for forming the allyl-isonitrile product 5 [13].

It would therefore appear from this first but crucial experiment that the diene insertion into the Mo-allyl bond is the favored process (albeit difficult) for Mo(II), whereas the homolytic cleavage of the Mo-allyl bond becomes preferred for Mo(III). It is still possible that, under the same experimental conditions, an insertion process for the Mo(III) complex might be more favored than for the Mo(II) complex, were it not for the isonitrile-induced reduction process. In principle, the presence of butadiene in place of tert-butylisonitrile (e.g. under the diene polymerization conditions) might reduce the drive toward the reduction process in favor of the insertion process, and the diene polymerization might be truly catalyzed by the Mo(III) $[1]^{+}$system. The results of the isonitrile experiments, however, cast a doubt on this hypothesis.

\section{Electrophilic attack of the allyl vs. diene}

The availability of more isomers of the same compound (1a, $\mathbf{1 b}$ and $\mathbf{1 c})$ that are inert toward isomerization has presented other interesting opportunities. This is apparently the first system where slowly interconverting isomers differ for the coordination mode of both allyl and diene ligands. Their relative reactivity can therefore be studied independently as a function of allyl and diene coordination mode.

The reactivity of the three isomers of $\mathbf{1}$ toward protons differs in terms of rate and position of attack. A reaction with $\mathrm{CH}_{3} \mathrm{COOH}$ establishes the order of reactivity $\mathbf{1 a}>\mathbf{1 b} \gg \mathbf{1 c}\left(t_{1 / 2} \approx 10 \mathrm{~min}\right.$ for $\mathbf{1 a}, 26 \mathrm{~min}$ for $\mathbf{1 b}$, and several days for $\left.1 \mathbf{c}\right)$. Since the isomerization of $\mathbf{1 b}$ to $\mathbf{1 a}$ has a $t_{1 / 2}$ of $6.5 \mathrm{~h}$, the protonation of $\mathbf{1 b}$ must occur directly and not via the isomer 1a. This difference in reactivity explains the facile separation of 1c from the other isomers by chromatography on a silica column: while 1a and $\mathbf{1 b}$ are irreversibly trapped by the silica, the less reactive 1c resists protonation and is eluted unchanged. While $\mathbf{1 a}$ and $\mathbf{1 b}$ are selectively protonated at the allyl ligand and yield products deriving from the elimination of propene, 1c shows both protonation at the allyl or at the diene depending on the solvent. The results of various experiments under different conditions and their mechanistic interpretation are rather elaborate [14]. A simplified picture showing the salient results is given in Scheme 7. Points of interest are as follows. Upon elimination of propene from $\mathbf{1 a}$ in the presence of butadiene, a product of stoichiometry $\left.[\mathrm{CpMo} \text { (butadiene) })_{2}\right]^{+} \mathrm{BF}_{4}^{-}$, which contains one $s$-cis and one s-trans diene ligand (complex 3) is obtained. This compound exchanges the s-trans butadiene ligand to give compounds 6 (with $\mathrm{Bu}^{\mathrm{t}} \mathrm{NC}$ ) and 7 (with $\mathrm{MeCN}$ ). Compound 1c yields products of formal allyl protonation in less polar solvents (toluene, THF) and products of formal diene protonation in $\mathrm{MeCN}$. Upon allyl protonation and propene elimination, an additional butadiene ligand coordinates either in the $s$-cis mode to afford compound $\mathbf{3}$, or in the s-trans mode to afford a hypothetical (unobserved) intermediate $\mathbf{8}$ which immediately collapses to the observed product of diene-diene coupling 9. The ligand $\mathrm{S}$ is a trapping solvent (THF, acetone- $\mathrm{d}^{6}$ or $\mathrm{CD}_{3} \mathrm{CN}$ ) or a two- 


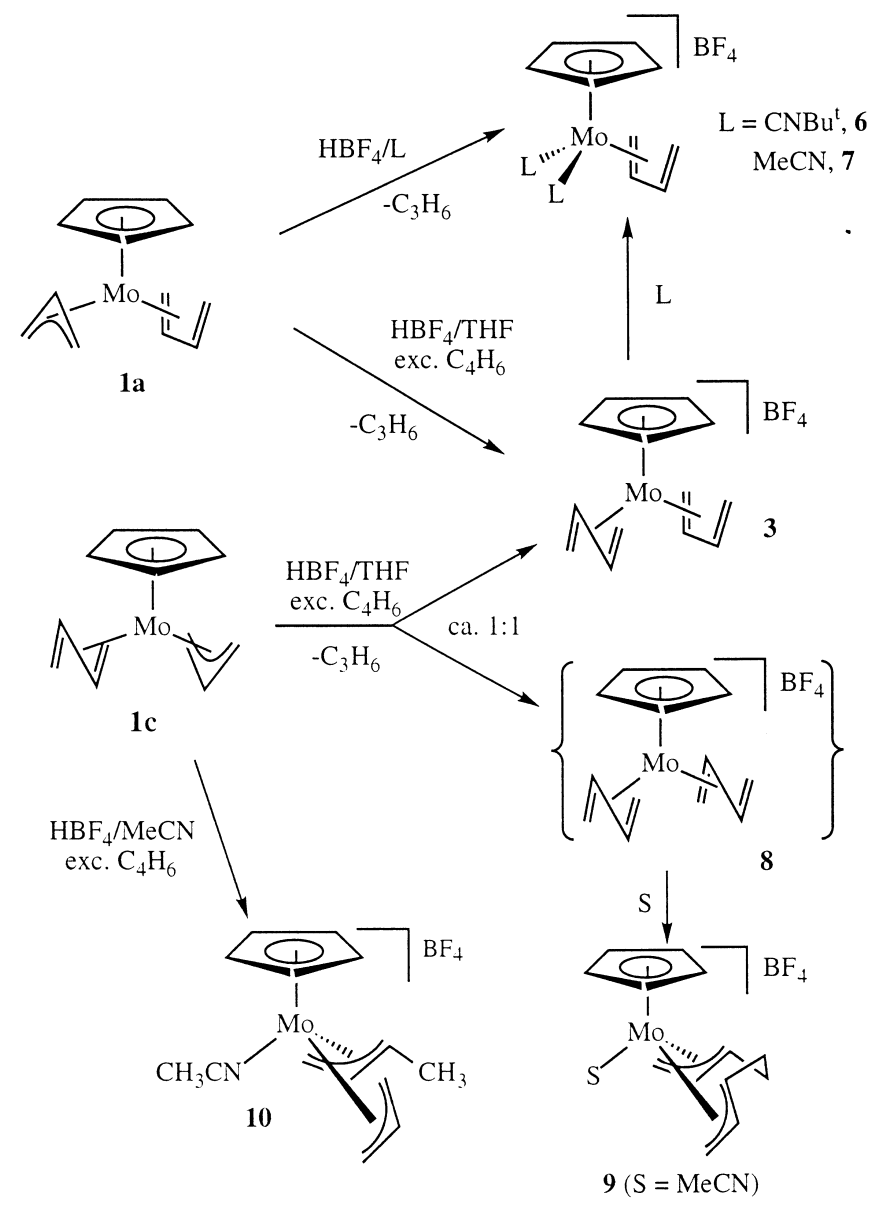

Scheme 7.

electron ligand (e.g. $\mathrm{PMe}_{3}$ ) subsequently added for NMR characterization purposes. In the absence of donor molecules, the $\mathrm{S}$ position could be occupied by the $\mathrm{BF}_{4}^{-}$ counterion or by an $\eta^{2}$-butadiene ligand. Protonation of $1 \mathrm{c}$ in $\mathrm{MeCN}$, on the other hand, affords the bis-allyl complex $\mathbf{1 0}$ which subsequently slowly decomposes by regioselective allyl-allyl coupling (vide infra).

It can immediately be imagined that complexes $\mathbf{3}$ and $\mathbf{9}$ may be implicated in the catalyzed dimerization of butadiene (see Section 3). Complex 9 would only require an allyl-allyl coupling, while complex $\mathbf{3}$ would require a diene-diene coupling followed by an allyl-allyl coupling. All these processes are widely precedented for other metal systems $[15,16]$. It can be further and rather easily imagined that these processes may be catalytic in the presence of excess butadiene. Thus, the current state of thinking is that complexes $\mathbf{1 a}, \mathbf{1 b}$ and $\mathbf{1 c}$ are responsible for the formation of the butadiene polymers, while an adventitious protonation process might generate 
species such as $\mathbf{3}$ and $\mathbf{9}$, which promote the dimerization processes. In agreement with this hypothesis, a thermal decomposition study of complex 9 was found to generate cyclooctadiene selectively. Further studies would obviously be needed to fully explore the mechanism of regiocontrol for this diene-diene coupling process.

Other allyldiene or bis-allyl complexes of Mo(II) and Mo(III) have become available by nucleophilic addition processes (see Section 5 ). The protonation studies of these materials show the following features (see Scheme 8): protonation of the syn-allyl ligand in compound $\mathbf{1 1}$ occurs regioselectively to the least substituted carbon and leads stereoselectively to the trans olefin. Protonation of the allyl ligand in the paramagnetic compound $\mathbf{1 2}$ equally occurs regioselectively. The formation of a mixture of cis and trans 2-pentenes from this experiment indicates that compound 12 is a mixture of isomers. This cannot be established from the analysis of the EPR spectrum of $\mathbf{1 2}$.

As a conclusion of this section, we have established that the allyl ligands in both neutral Mo(II) and neutral Mo(III) complexes are susceptible to regioselective electrophilic addition of protons. We have further established that the $s$-trans butadiene ligand in 1c competes with the allyl ligand for the proton, while the $s$-cis butadiene ligand in $\mathbf{1 a}$ or in $\mathbf{1 b}$ is never attacked. Computational studies involving DFT-B3LYP geometry optimizations have shown that the partial charges on the various ligand atoms (see Fig. 3) are more or less in agreement with the observed trend of reactivity, in agreement with the idea that protonation reactions are charge controlled. Finally, we have found that the protonation in the presence of butadiene leads to a single isomer of a cationic bis-butadiene complex, which contains the two diene ligands in two different coordination modes, and to a cationic bis-allyl product deriving from a diene-diene coupling. The latter complexes may play a role in the Mo-catalyzed butadiene dimerization discussed in Section 3.

\section{Nucleophilic addition vs. ligand substitution}

The availability of the kinetically stable and isomerically pure complex $\mathbf{3}$ has allowed, for the first time, a detailed study of the comparative reactivity of cis and

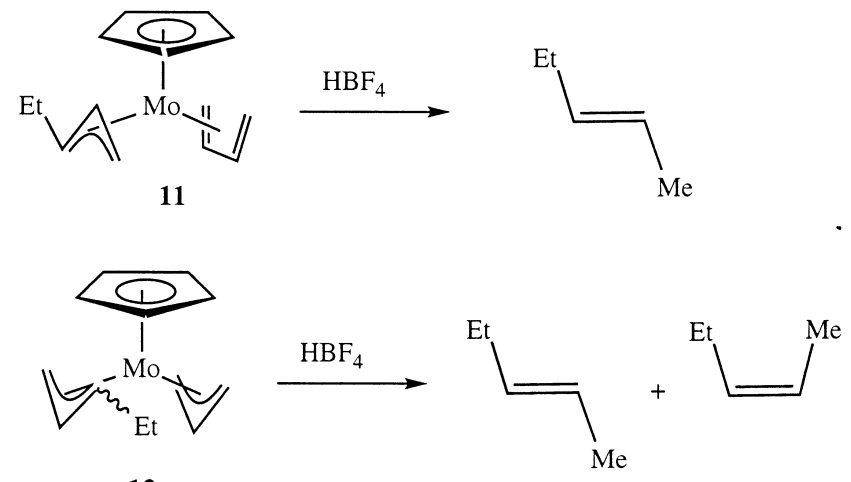

12

Scheme 8. 

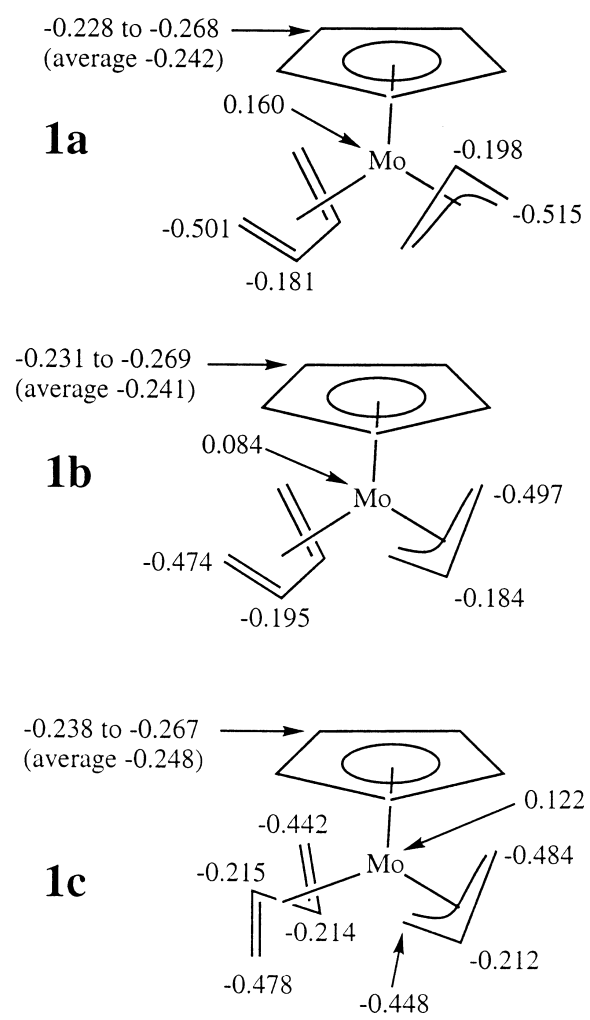

Fig. 3. Effective atomic charges for compounds 1a, 1b and 1c from DFT-B3LYP calculations.

trans diene ligands on the same metal center toward nucleophilic reagents [17]. The only other example of a bis-diene compound where the two diene ligands are coordinated in the $s$-cis and $s$-trans mode appears to be $\mathrm{CpNb}\left(\eta^{4}-\mathrm{C}_{4} \mathrm{H}_{6}\right)_{2}$, which is isoelectronic with $\mathbf{3}$, but this was obtained in admixture with the bis-s-cis isomer [18]. Other compounds containing a coordinated s-trans ligand are rare [18-26], and studies of the ligand reactivity are often thwarted by rapid ligand isomerization $[22,25]$.

Depending on the nature of the nucleophilic reagent, two different reaction pathways have been observed. These consist of substitution and nucleophilic addition (see Scheme 9) and both involve the s-trans ligand, while the s-cis butadiene ligand behaves in each case as a simple spectator ligand like the $\mathrm{Cp}$ ring. The nucleophilic attack resulting in addition takes place regioselectively at the endo position of the $s$-trans butadiene ligand, namely the position closest to the $\mathrm{Cp}$ ring. This is demonstrated by a detailed study of the product of methyl attack, the ethylallyl derivative 11. In principle, product 11 could also be obtained by exo attack, followed by rapid isomerization of the resulting product 11' (see Scheme 10). However, this is excluded because we have been able to synthesize $11^{\prime}$ selectively by an alternative route 
(a) substitution
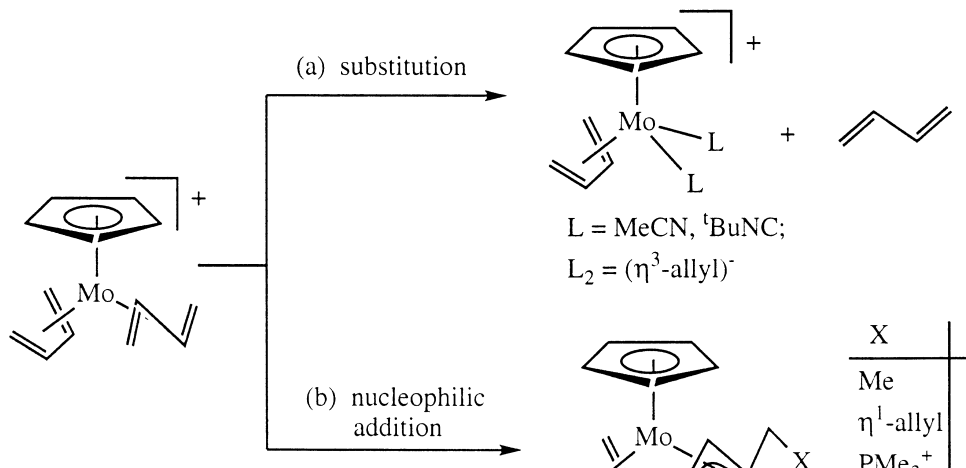

$\mathrm{L}=\mathrm{MeCN},{ }^{\mathrm{t}} \mathrm{BuNC}$;

$\mathrm{L}_{2}=\left(\eta^{3} \text {-allyl }\right)^{-}$

Scheme 9.

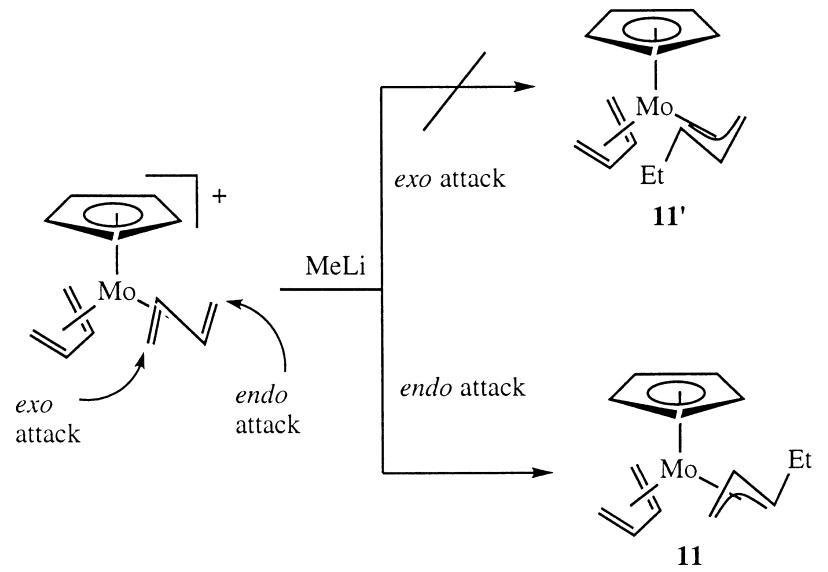

Scheme 10.
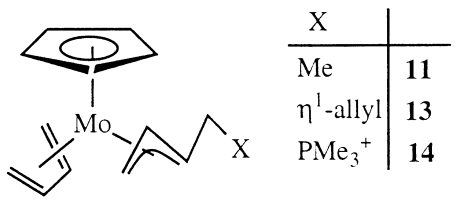


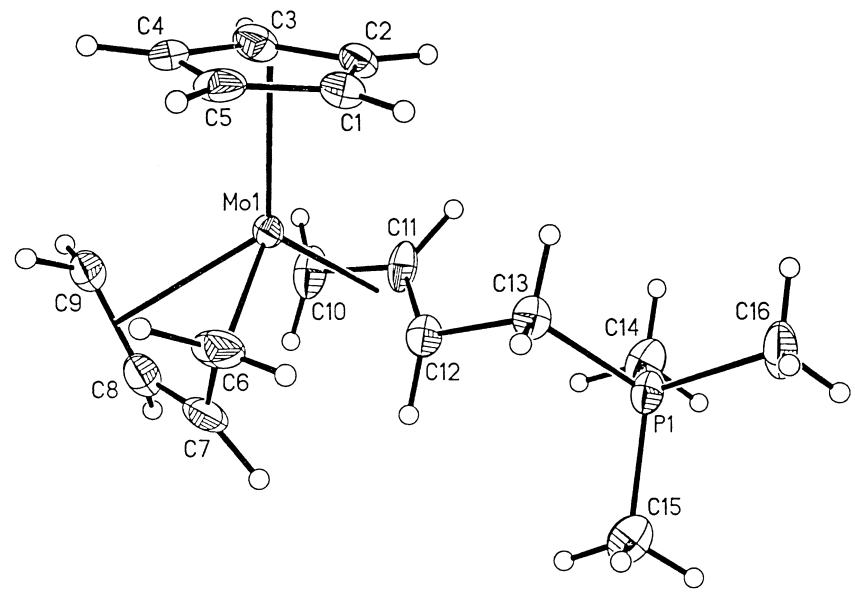

Fig. 4. An ORTEP view of complex 15. Copyright 1997 American Chemical Society.

the most to the LUMO. By far, the two biggest contributors to the LUMO are the metal and the endo carbon atom of the s-trans butadiene ligand. All other ligand atoms provide minimal contribution (see Fig. 5). The computational study has also led to the conclusion that the Mo-diene bond is weaker for the s-trans ligand and that this is due to both weaker $\sigma$ bonding and weaker $\pi$ back-bonding components [14]. Thus, this is an interesting situation where weaker bonding corresponds to stronger activation, both in terms of the electrophilic addition to 1 (see Section 4), and the nucleophilic addition to $\mathbf{3}$ discussed in this section. The position of attack is always at the $s$-trans and never at the $s$-cis butadiene.

It is interesting to observe the inversion of reactivity for the s-trans butadiene ligand on going from 1c (proton addition; no nucleophilic addition) to the isoelectronic 7 (nucleophilic addition). The susceptibility toward nucleophilic attack is enhanced, as expected, by the introduction of a positive charge. One could also expect a similar effect upon metal oxidation, but the reactivity of the Mo(III)-

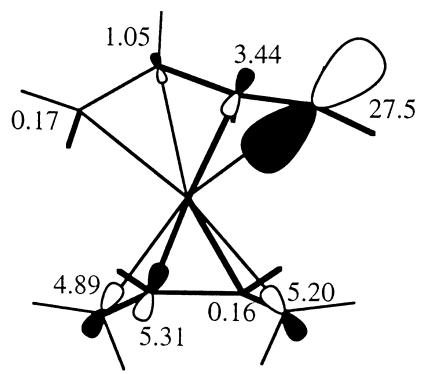

Fig. 5. Qualitative view of the LUMO composition, limited to the two diene ligands, for complex $\left[\mathrm{CpMo}\left(\text { s-cis-supine- } \mathrm{C}_{4} \mathrm{H}_{6}\right)\left(\text { s-trans }-\mathrm{C}_{4} \mathrm{H}_{6}\right)\right]^{+}$. Numbers represent the per cent participation of atomic orbitals to the LUMO. Calculations are by the Fenske-Hall method on the DFT-B3LYP geometry-optimized molecule. 


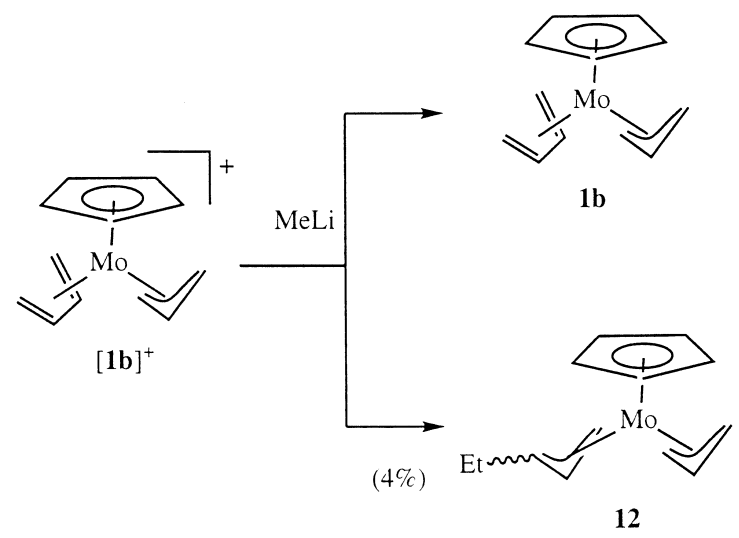

Scheme 11 .

coordinated $s$-trans butadiene could not be studied, because complex $[\mathbf{1 c}]^{+}$isomerizes too rapidly to the $s$-cis isomer $[\mathbf{1 b}]^{+}$(Scheme 3 ). However, even the $s$-cis butadiene ligand becomes sufficiently reactive when coordinated to Mo(III) to undergo a nucleophilic addition by methyllithium (Scheme 11). The main product of this reaction is the one-electron reduction product $\mathbf{1 b}$. However, $4 \%$ of the reaction yields the addition product $\mathbf{1 2}$ as shown by quantitative EPR spectroscopy. The EPR spectrum does not allow a determination of stereochemistry for the ethylallyl ligand. However, the result of the subsequent protonation (Scheme 8, see Section 4) suggests that a mixture of syn and anti isomers of $\mathbf{1 2}$ is obtained.

\section{Allyl-allyl coupling}

Another basic reaction that has attracted our attention for this class of organometallic compounds is the allyl-allyl coupling. This is, as mentioned above, a required step for the catalytic butadiene dimerization process and it is also involved in butadiene cyclotrimerization [27]. The metal-assisted coupling of allyl ligands to afford 1,5-hexadiene is a widely known reaction [27-29]. However, it was not precedented for molybdenum except for the formation of a 2,4-hexadiene complex by interaction of propene with a "violet solution", presumably containing $\left(\eta^{6}-\mathrm{C}_{6} \mathrm{H}_{6}\right) \mathrm{Mo}\left(\eta^{3}-\mathrm{C}_{3} \mathrm{H}_{5}\right)(\mu-\mathrm{Cl})_{2} \mathrm{AlClEt}$. This process was proposed to involve an allyl-allyl coupling on a proposed but not observed bis-allyl Mo(IV) intermediate to afford a coordinated 1,5-hexadiene ligand, followed by isomerization [30].

A spontaneous coupling has been reported to occur upon ligand addition to the $\mathrm{Cr}$ (III) complex $\mathrm{CpCr}\left(\eta^{3}-\mathrm{C}_{3} \mathrm{H}_{5}\right)_{2}$ [31], while the corresponding Mo complex 2 does not undergo a similar process under mild conditions $[6,32,33]$, in accord with the expected greater stability of the heavier metal in the higher oxidation state. We have now found that 2 yields a mixture of propene and 1,5-hexadiene in a ca. 1:2 ratio upon warming to the $\mathrm{MeCN}$ reflux temperature [13]. The formation of propene may be attributed to an allyl radical elimination from $\mathbf{2}$, similar to the reaction with 
tert-butylisonitrile (Scheme 6). The 1,5-hexadiene major product, on the other hand, is not likely to arise from a radical recombination reaction, because the $\mathrm{C}-\mathrm{H}$ bonds of the $\mathrm{MeCN}$ solvent are ca. $7 \mathrm{kcal} / \mathrm{mol}$ weaker than the propene allylic $\mathrm{C}-\mathrm{H}$ bonds [34]. We have therefore proposed that this compound arises from a metal-assisted intramolecular process [13].

In any case, this difficult Mo(III)-mediated allyl-allyl coupling process becomes much easier upon one-electron oxidation, because 1,5-hexadiene is immediately obtained at room temperature upon treatment of compound 2 with $\mathrm{Cp}_{2} \mathrm{FePF}_{6}$ in either $\mathrm{MeCN}$ or acetone. No intermediate bis-allyl Mo(IV) complex or Mo(II)-hexadiene complex has been observed in these solvents, but the use of trapping ligands such as $\mathrm{Bu}^{\mathrm{t}} \mathrm{NC}$ or butadiene has led to the observation of mixtures of complexes $\left[\mathrm{CpMo}\left(\mathrm{CNBu}^{t}\right)_{3}\left(\eta^{2}-\mathrm{CH}_{2}=\mathrm{CH}-\mathrm{CH}_{2} \mathrm{CH}_{2} \mathrm{CH}=\mathrm{CH}_{2}\right)\right]^{+}, \quad \mathbf{1 5}$, and $\left[\mathrm{CpMo}\left(\mathrm{CNBu}^{t}\right)_{4}\right]^{+}, \mathbf{1 6}$, or $\mathbf{6}$ and $\mathbf{9}$, respectively, see Scheme 12. All these reactions are believed to occur via analogous $\left[\mathrm{CpMo}(\mathrm{L})\left(\eta^{3}-\mathrm{C}_{3} \mathrm{H}_{5}\right)_{2}\right]^{+}$intermediates, 17 .

It is therefore interesting to note the remarkable difference in stability for the
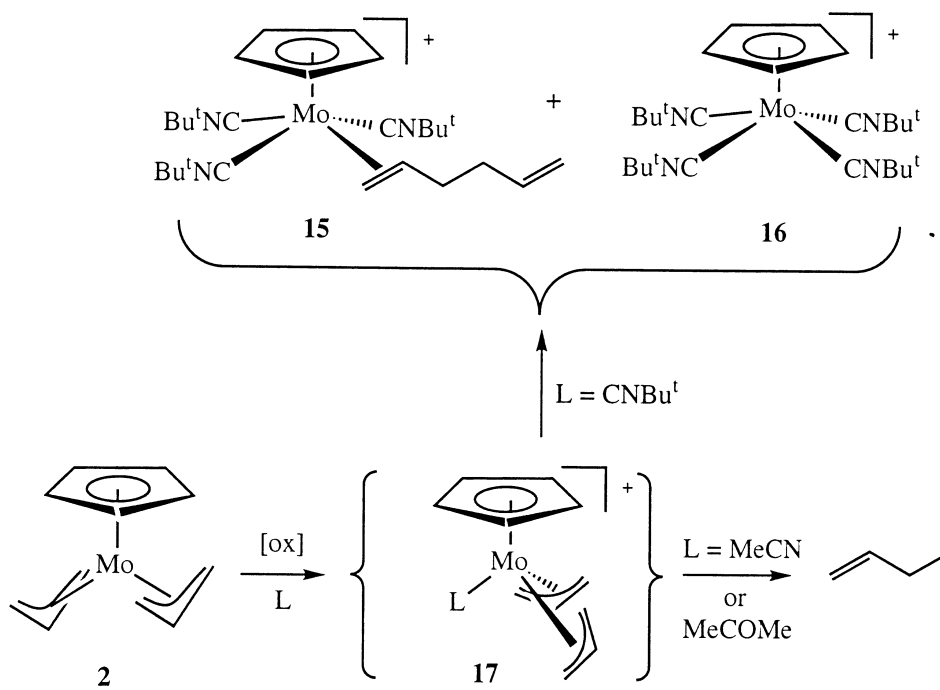

2

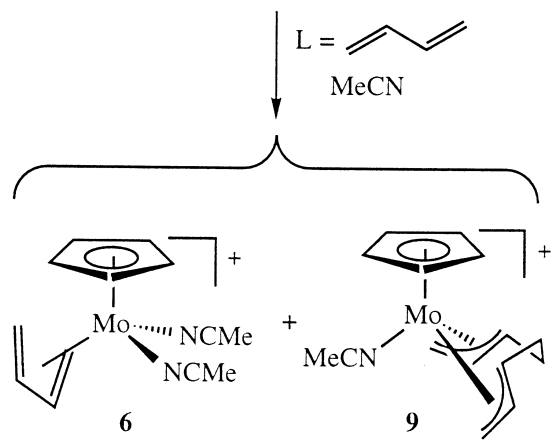

Scheme 12. 

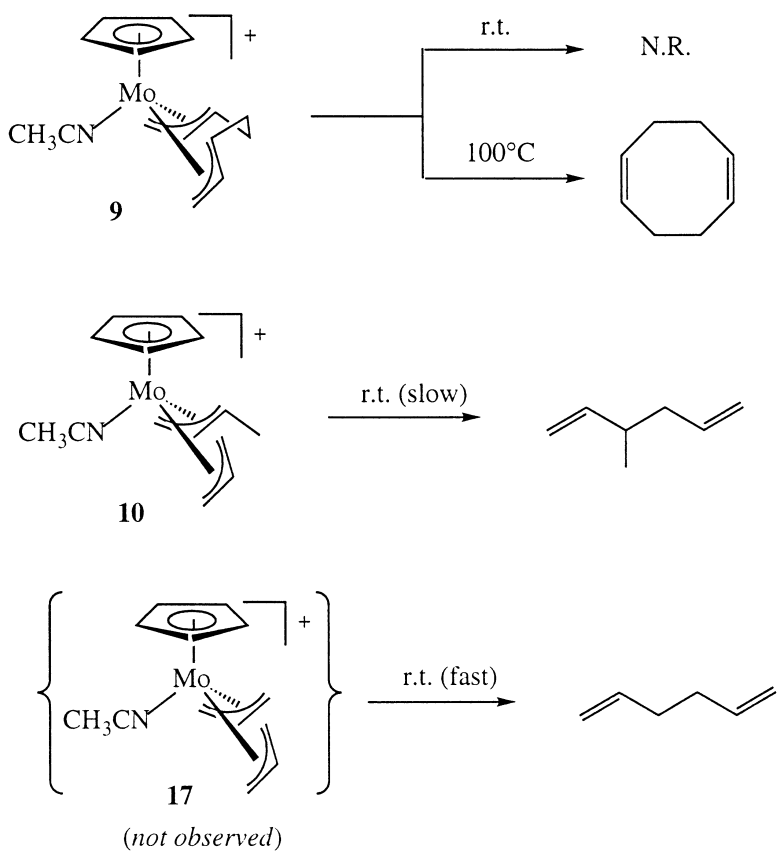

Scheme 13.

different Mo(IV) bis-allyl complexes that we have encountered in this study (see Scheme 13). Complex 9 is indefinitely stable at room temperature and decomposes only upon reflux in $\mathrm{MeCN}$ to afford cyclooctadiene. Complex $\mathbf{1 0}$ can be observed at room temperature in $\mathrm{MeCN}$ but slowly decomposes to the 3-methyl-1,5-hexadiene coupling product. Finally, complex $\mathbf{1 7}$ decomposes rapidly at room temperature and is not observed. The allyl substitution pattern appears to strongly control the rate of allyl-allyl coupling. In addition, the coupling process is remarkably regioselective, giving only one coupling product for both complexes 9 and $\mathbf{1 0 .}$

In conclusion, the different reactivity observed for the complexes of Mo(III) and Mo(IV) toward allyl-allyl coupling points again to the involvement of Mo(II) bisdiene complexes, via Mo(IV) bis-allyl complexes, in the catalyzed butadiene dimerization. A clarification of the mechanism of regiocontrol in the dimerization process (that is, the observed formation of cyclooctatetraene and vinylcyclohexene, see Scheme 4) would require further study.

\section{Conclusions and perspectives}

The development of system 1, an 18-electron Mo(II) compound containing the simplest 5-C ligand (Cp), the simplest 4-C ligand (butadiene), and the simplest 3-C ligand (allyl), and of the corresponding one-electron oxidation product, the 17-electron Mo(III) system $[\mathbf{1}]^{+}$, has provided interesting new information on the 
basic reactivity of the diene and allyl ligands as a function of the oxidation state. A more facile accessibility of electronically less saturated intermediates for the Mo(III) system relative to the Mo(II) system is demonstrated. While the addition of neutral ligands induces a difficult insertion of the diene into the Mo-allyl bond for Mo(II), the homolytic scission of the Mo-allyl bond becomes preferred for Mo(III). The serendipitous discovery of slow ligand isomerizations (prone vs. supine for the allyl ligand, s-cis supine vs. s-trans for the butadiene ligand) in the Mo(II) manifold has allowed detailed studies of the reactivity of both ligands as a function of the coordination mode. In brief, our studies have shown that an apparently simple organometallic system may in fact lead to a rather complicated behavior. Additional studies, both experimental and theoretical, on these and other redox-related species and on a wider variety of catalytically relevant elementary steps are necessary before the potential catalytic application of paramagnetic complexes may be brought to a more predictive level.

\section{Acknowledgements}

This research has been conducted at the University of Maryland during the one year prior to and the one year following RP's move to the Universite de Bourgogne. Support from the NSF (CHE-9508521) is gratefully acknowledged. RP would also like to thank the Conseil Régional de Bourgogne for generous funding that will permit the continuation of these studies at the Universite de Bourgogne.

\section{References}

[1] R. Poli, Chem. Rev. 96 (1996) 2135-2204.

[2] F. Calderazzo, G. Fachinetti, C. Floriani, J. Am. Chem. Soc. 96 (1974) 3695-3696.

[3] H.H. Brintzinger, L.L. Lohr Jr.,, K.L.T. Wong, J. Am. Chem. Soc. 97 (1975) 5146-5155.

[4] R. Poli, Acc. Chem. Res. 30 (1997) 494-501.

[5] J.K. Burdett, J. Chem. Soc., Faraday Trans. II 70 (1974) 1599-1613.

[6] P.W. Jolly, C. Krüger, C.C. Romão, M.J. Romão, Organometallics 3 (1984) 936-937.

[7] R. Poli, J. Coord. Chem. B29 (1993) 121-173.

[8] J.L. Davidson, K. Davidson, W.E. Lindsell, N.W. Murrall, A.J. Welch, J. Chem. Soc., Dalton Trans. (1986) $1677-1688$.

[9] L.-S. Wang, J.C. Fettinger, R. Poli, J. Am. Chem. Soc. 119 (1997) 4453-4464.

[10] R.G. Linck, B.E. Owens, R. Poli, A.L. Rheingold, Gazz. Chim. Ital. 121 (1991) 163-168.

[11] R. Poli, in: W.A. Herrmann (Ed.), Synthetic Methods of Organometallic and Inorganic Chemistry (Herrmann/Brauer), vol. 8, Georg Thieme, Stuttgart, 1997, pp. 101-102.

[12] W.C. Trogler, in: W.C. Trogler (Ed.), Organometallic Radical Processes, vol. 22, Elsevier, Amsterdam, 1990, pp. 306-337.

[13] R. Poli, L.-S. Wang, in press to Polyhedron.

[14] R. Poli, L.-S. Wang, J. Am. Chem. Soc., 120 (1998) 2831-2842.

[15] G. Wilkinson, F.G.A. Stone, E.W. Abel, Comprehensive Organometallic Chemistry II, Pergamon, Oxford, 1995.

[16] G. Wilkinson, R.D. Gillard, J.A. McCleverty, Comprehensive Coordination Chemistry, Pergamon Press, Oxford, 1988. 
[17] L.-S. Wang, J.C. Fettinger, R. Poli, R. Meunier-Prest, Organometallics, 17 (1998) 2692-2701.

[18] T. Okamoto, H. Yasuda, A. Nakamura, Y. Kai, N. Kanehisa, N. Kasai, J. Am. Chem. Soc. 110 (1988) 5008-5017.

[19] G. Erker, C. Kruger, G. Muller, Adv. Organomet. Chem. 24 (1985) 1-39.

[20] N.J. Christensen, A.D. Hunter, P. Legzdins, Organometallics 8 (1989) 930-940.

[21] S.A. Benyunes, J.P. Day, M. Green, A.W. Al-Saadoon, T.L. Waring, Angew. Chem., Int. Ed. Engl. 29 (1990) 1416-1417.

[22] S.A. Benyunes, A. Binelli, M. Green, M.J. Grimshire, J. Chem. Soc., Dalton Trans. (1991) 895-904.

[23] N.J. Christensen, P. Legzdins, F.W.B. Einstein, R.H. Jones, Organometallics 10 (1991) 3070-3080.

[24] N.J. Christensen, P. Legzdins, J. Trotter, V.C. Yee, Organometallics 10 (1991) 4021-4030.

[25] W.-J. Vong, S.-M. Peng, W.-J. Lin, R.-S. Liu, J. Am. Chem. Soc. 113 (1991) 573-582.

[26] C. Carfagna, R.J. Deeth, M. Green, M.F. Mahon, J.M. McInnes, S. Pellegrini, C.B. Woolhouse, J. Chem. Soc., Dalton Trans. (1995) 3975-3985.

[27] G. Wilke, J. Organomet. Chem. 200 (1980) 349-364.

[28] R. Baker, Chem. Rev. 73 (1973) 487-530.

[29] J. Tsuji, Adv. Organomet. Chem. 17 (1979) 141-193.

[30] M.L.H. Green, J. Knight, J. Chem. Soc., Dalton Trans. (1974) 311-319.

[31] P. Betz, A. Döhring, R. Emrich, R. Goddard, P.W. Jolly, C. Krüger, C.C. Romão, K.U. Schönfelder, Y.-H. Tsay, Polyhedron 12 (1993) 2651-2662.

[32] O. Andell, R. Goddard, S. Holle, P.W. Jolly, C. Krüger, Y.H. Tsay, Polyhedron 8 (1989) $203-209$.

[33] P.W. Jolly, Acc. Chem. Res. 29 (1996) 544-551.

[34] R.C. Weast, CRC Handbook of Chemistry and Physics, CRC Press, Cleveland, OH, 1976. 